\title{
Case - Incorporating modern technology with traditional ceremony of Brit Milah during the COVID-19 pandemic
}

\author{
Min Joon Lee, MD ${ }^{1,2}$; Alexander B. Koven, MD ${ }^{1,2}$; Michael E. Chua, MD ${ }^{1,2,3}$; Martin A. Koyle, MD MSc ${ }^{1,2}$
}

'Division of Urology, Department of Surgery, University of Toronto, ON, Canada; ${ }^{2}$ Division of Urology, Department of Surgery, Hospital for Sick Children, Toronto, ON, Canada; ${ }^{3}$ nstitute of Urology, St. Luke's Medical Center, Quezon City, NCR, Phillipines

Cite as: Lee MJ, Koven AB, Chua ME, et al. Case - Incorporating modern technology with traditional ceremony of Brit Milah during the COVID-19 pandemic. Can Urol Assoc J 2021;15(3):E187-8. http://dx.doi.org/10.5489/cuaj.7120

\section{Introduction}

Circumcision is one of the most common surgical procedures performed, of which half are done for cultural or religious reasons. ${ }^{1}$ For Jewish people, it is more than just the cutting of skin. It is associated with a traditional ceremony called Brit Milah, which includes both prayer and celebration among family and friends. While it is typically done on the eighth day of life, boys with congenital penile abnormalities, extreme prematurity, or comorbid medical conditions have their Brit Milah deferred until their health status can be optimized.

At the Hospital for Sick Children (SickKids), a unique program has been established for a deferred Brit Milah beyond the newborn period (>6 months) under general anesthesia, which includes family members being present in the operating room (OR) for the ceremony itself, after which any indicated surgical procedures can be completed. ${ }^{2}$ The COVID19 pandemic has impacted this program due to increased OR and hospital visitor restrictions.

We report the use of Zoom (Zoom Video Communications, Inc.) as a virtual platform, in order to allow OR Brit Milah, along with corrective penile surgery, to be performed with family involvement during the ceremonial portion of the procedure.

\section{Case report}

A newborn Jewish boy was assessed shortly after birth for neonatal circumcision with Brit Milah. Severe congenital ventral penile curvature or chordee was noted, leading to a decision to delay the procedure until six months of age.

Due to COVID-19, chordee repair with Brit Milah was postponed. He was ultimately booked for Brit Milah with possible phalloplasty at 15 months old. It was the parents' strong preference to be present for the ceremony, as per their cultural and religious customs, but new rules introduced in response to COVID-19 prohibited family members from entering the OR. In order to avoid further delay while also respecting religious practices, the Brit Milah ceremony was held over a mobile phone using the Zoom virtual platform in the OR.

To begin, the surgeon generated a secure Zoom link invite under the licensed healthcare account. The link was sent to family members with associated secure passcodes. Only the authorized invitees were allowed to log onto the Zoom meeting. After equipment was tested, the patient was brought to the OR with mild sedation. He was intubated, prepped, and draped using standard sterile technique. A winter screen was used to cover the anesthesia machines and backgrounds. The camera from the OR's surgical lights was positioned towards the surgical site. While the primary surgeon was preparing to start the ceremony, the assistant held a phone with a built-in camera, microphone, and speaker, facing towards the surgeon and the patient (Fig. 1). This allowed the family to visualize both the surgical site and the ceremony simultaneously, as well as hear and respond. The Zoom meeting was then connected, allowing the patient's family to join and participate in the ceremony. This included making the first incision, which was a representative skin nick, as well as prayer and song. As per the family's request, the ceremony was recorded. Once the ceremony was complete, the Zoom meeting was disconnected and the surgeon proceeded with the phalloplasty using standard technique. ${ }^{3}$

\section{Discussion}

Since the COVID-19 pandemic began, SickKids Urology has been prioritizing cases and replacing in-person visits with virtual clinic platforms (e.g., telephone, Zoom, etc.) when possible. ${ }^{4}$ This case shows an innovative and adaptive approach to COVID-19 by not only offering clinical assessment virtually, but also performing a virtual Brit Milah ceremony in the OR.

The novel intraoperative Brit Milah developed at SickKids has been previously shown to yield high caregiver satisfaction, no additional OR time or postoperative complications, 


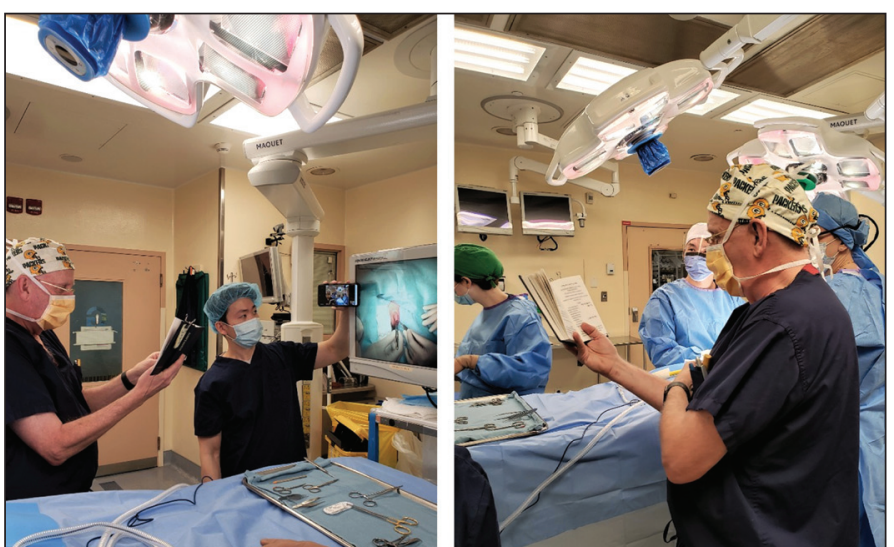

Fig. 1. Surgeon reciting a blessing during the virtual Brit Milah ceremony over Zoom.

and is an item most pediatric urologists consider important. ${ }^{2}$ In this case, the family of our patient greatly appreciated and approved of the virtual modification as a way to balance their religious beliefs and son's healthcare needs, especially as the planned operation had already been delayed.

During these unprecedented times, virtual platforms can be used creatively to help overcome challenges faced in our healthcare system, such as those created by restrictions on in-person visits and visitors. While the case discussed allowed a family to be virtually present for a religious ceremony in the OR during COVID-19, this can be applied to institutions that do not permit family members into the OR in general or have strict limitations on numbers. All family members, regardless of family size or geographic distribution, can be involved without added risks, such as contamination of sterile fields or distractions in the OR. Applications may also be broadened during this pandemic and extended after COVID-19 abates. Pediatric patients can be provided with a tablet connected to their family on their way from the preoperative area to the OR in order to reduce anxiety and discomfort. It is feasible to establish virtual intraoperative consultations to allow more efficient and flexible communication among surgeons when appropriate. Even in the outpatient surgical clinic setting, telecommunication for a selective group of patients (i.e., low-risk) may help reduce overall expenditures from patients (e.g., absence from professional duties, extensive travel, and associated costs). ${ }^{5}$

While there are numerous applications and benefits from incorporating virtual platforms into the OR, security must be further evaluated to maximize patient privacy and confidentiality. Many platforms claim to be compliant with Canadian and U.S. data protection regulations, but this must be carefully scrutinized before broad implementation.

\section{Conclusions}

The COVID-19 pandemic has resulted in increased OR and hospital visitor restrictions. Incorporating modern technology creatively, such as a reliable and secure virtual platform, may help overcome challenges faced in our healthcare system during and post-pandemic.

Competing interests: The authors report no competing personal or financial interests related to this work.

This paper has been peer-reviewed.

\section{References}

1. WHO/UNAIDS. Male circumcision: Global trends and determinants of prevalence, safety, and acceptability. World Heal Organ 2008:7.

2. Koven A, $O^{\prime}$ Kelly F, El-Ghazzaoui A, et al. Bringing Jewish ritual circumcision (Brit Milah) into the operating room: An analysis of surgical outcomes and satisfaction across families and Society of Pediatric Urology members. Urology In press 2020. hitps://doi.org/10.1016/i.urology.2020.12.038

3. Abdulwahab-Ahmed A, Mungadi IA. Techniques of male circumcision. J Surg Tech Case Rep 2013;5:1-7. https://doi.org/10.4103/2006-8808.118588

4. Keefe DT, Rickard M, Anderson P, et al. Prioritization and management recommendations of pediatric urology conditions during the COVID-19 pandemic. Can Urol Assoc J 2020;14:237-50. https://doi.org/10.5489/cuai.6693

5. Lee MJ, Kim JK, Pokarowski M, et al. Clinical and economic value of routine pathological examination of hernia sacs and scheduled clinic followups after inguinal hernia and hydrocele repair in a Canadian tertiary care children's hospital. J Pediatr Surg 2020;55:1463-69. https://doi.org/10.1016/i.jpedsurg. 2019.09.007

Correspondence: Dr. Min Joon Lee, Division of Urology, The Hospital for Sick Children, Toronto, ON, Canada; minjoon.lee@mail.utoronto.ca 